SUPPORTING INFORMATION

\title{
Structure and Dynamics of the Lithium Ion Solvation Shell in Ureas
}

\author{
Xiaobing Chen, $\uparrow$ Kristen D. Fulfer, $†$ Kaylee T. Woodard, $\uparrow$ Daniel G. Kuroda $†$
}

$†$ Department of Chemistry, Louisiana State University, Baton Rouge, Louisiana 70803, United States

†. Chemistry Program, Centre College, Danville, KY, 40422, USA

*Address correspondence to dkuroda@1su.edu

FTIR SPECTRA OF PURE UREAS AND UREAS DILUTED IN DMSO AND IN THF

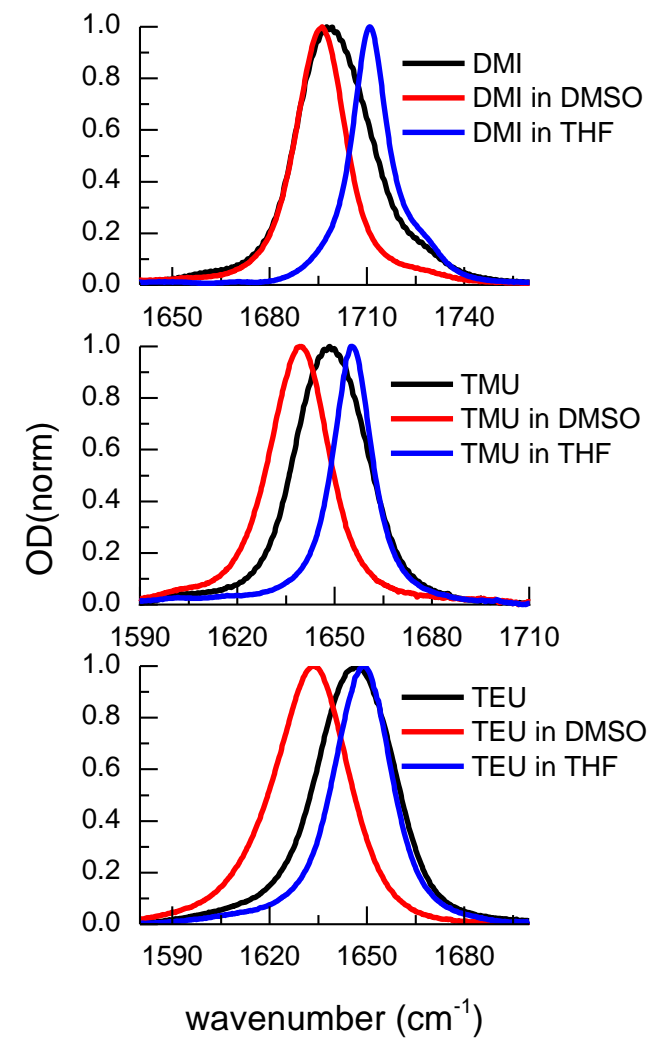

FIGURE S1. FTIR spectra of ureas and ureas diluted in DMSO and THF. From top to bottom, the spectra are from DMI, TMU and TEU, respectively. Black, red and blue represent neat ureas, ureas in DMSO and ureas in THF, respectively. 


\section{POLARIZATION DEPENDENCE OF THE 2DIR SPECTRUM}
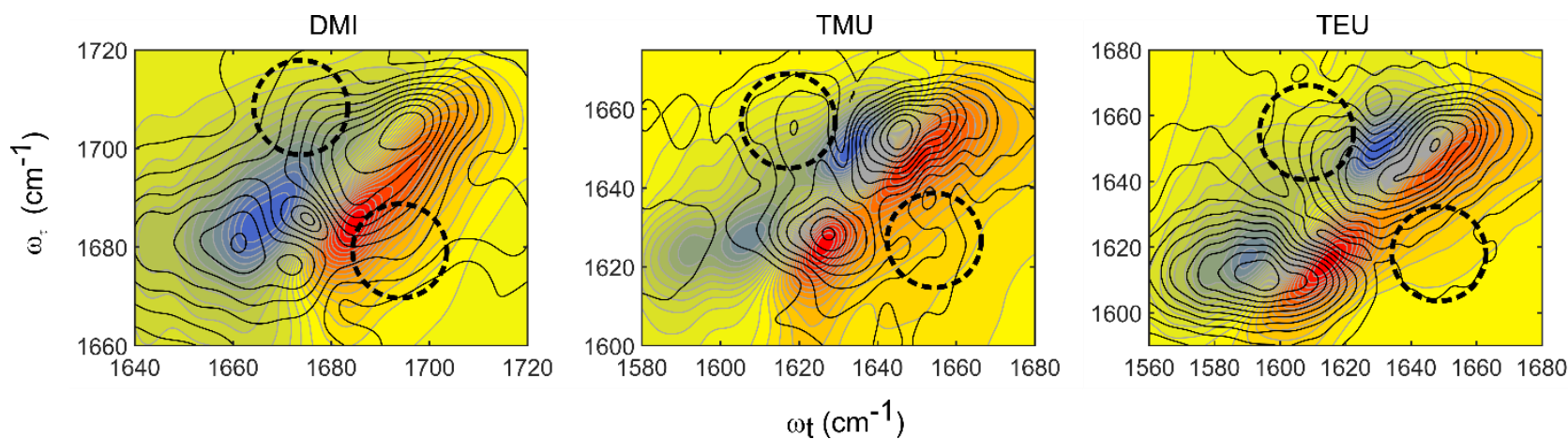

Figure S2. Absorptive 2DIR spectra of DMI, TMU and TEU at $\mathrm{T}_{\mathrm{W}}=0 \mathrm{ps}$ in blue and red contours. The black contours show the absolute value of the different 2DIR spectra with $\langle\mathrm{XXXX}\rangle$ and $\langle\mathrm{XX}, \mathrm{Y}+\mathrm{X}, \mathrm{Y}+\mathrm{X}\rangle$. The dashed circles show the location of the possible off-diagonal features.

2DIR SPECTRA AND CLS OF A DILUTE SOLUTION OF TMU IN BC WITH Li+

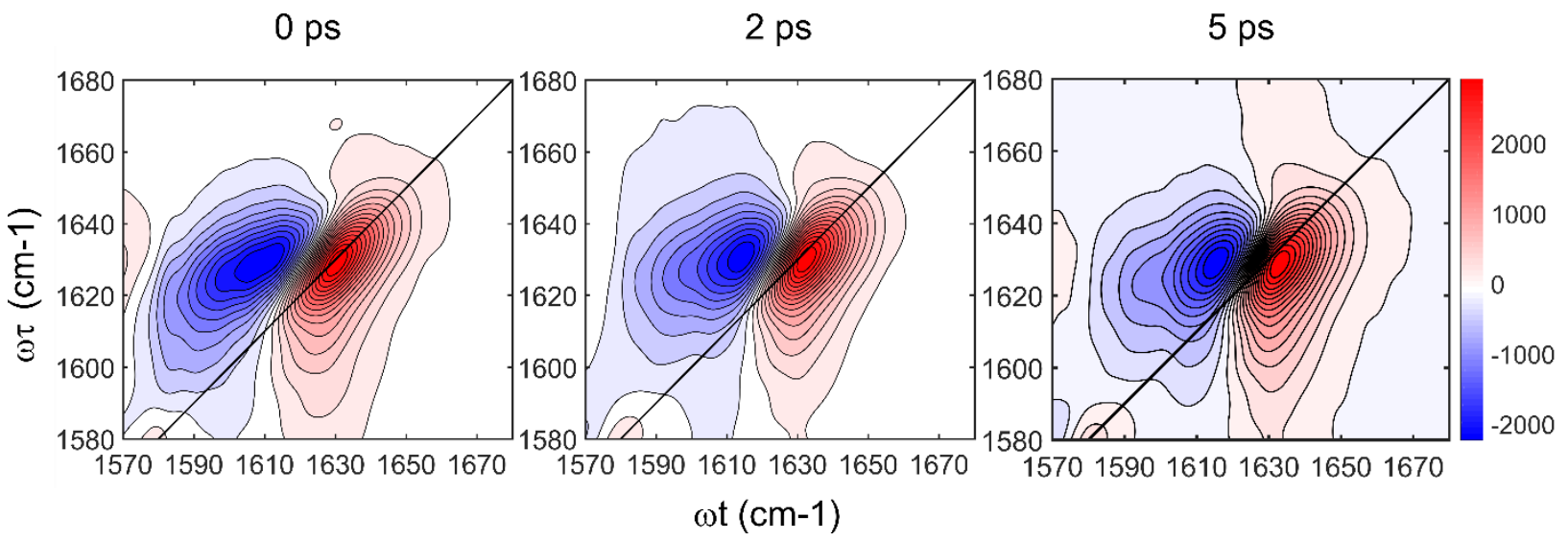

FIGURE S3. 2DIR spectra of dilute urea electrolyte, 0.1 LiTFSI in TMU and BC (molar ratio of Li:TMU:BC $=2: 1: 17$ ). Left to right: 2DIR spectra at 0,2 and $5 \mathrm{ps}$, respectively. CLS of the coordinated band for the diluted urea solution.

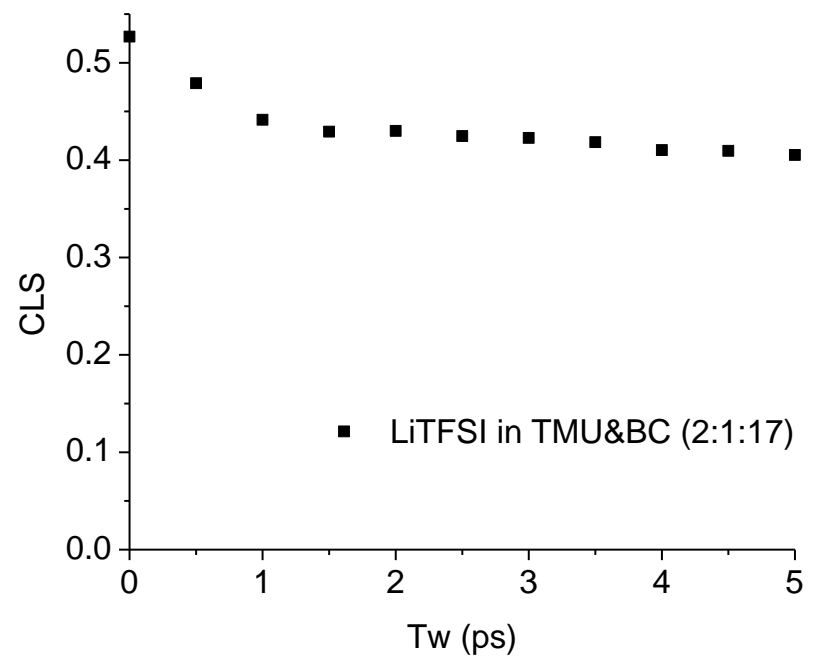

FIGURE S4. CLS computed for the coordinated band of the 2DIR spectra (Figure S3) of the dilute urea. 
COMPARISON BETWEEN CALCULATED ( $\left.\Delta v_{\text {calc. }}\right)$ AND EXPERIMENTAL $\left(\Delta v_{\text {exp. }}\right)$ FREQUENCY DIFFERENCE

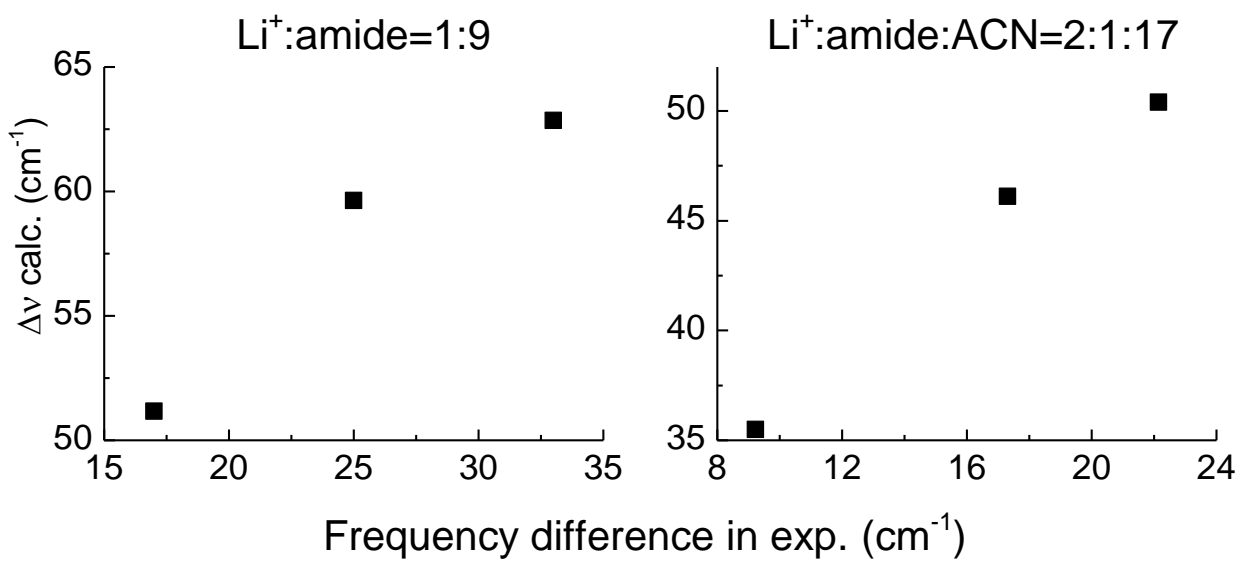

FIGURE S5. Frequency difference from DFT vs. frequency difference from FTIR. The regression coefficient is found to be $\mathrm{R}^{2}=0.97$ (pure urea) and $\mathrm{R}^{2}=0.99$ (dilute urea).

\section{FTIR DATA OF DILUTE EXPERIMENTS WITH THF, BC AND ACETONITRILE}
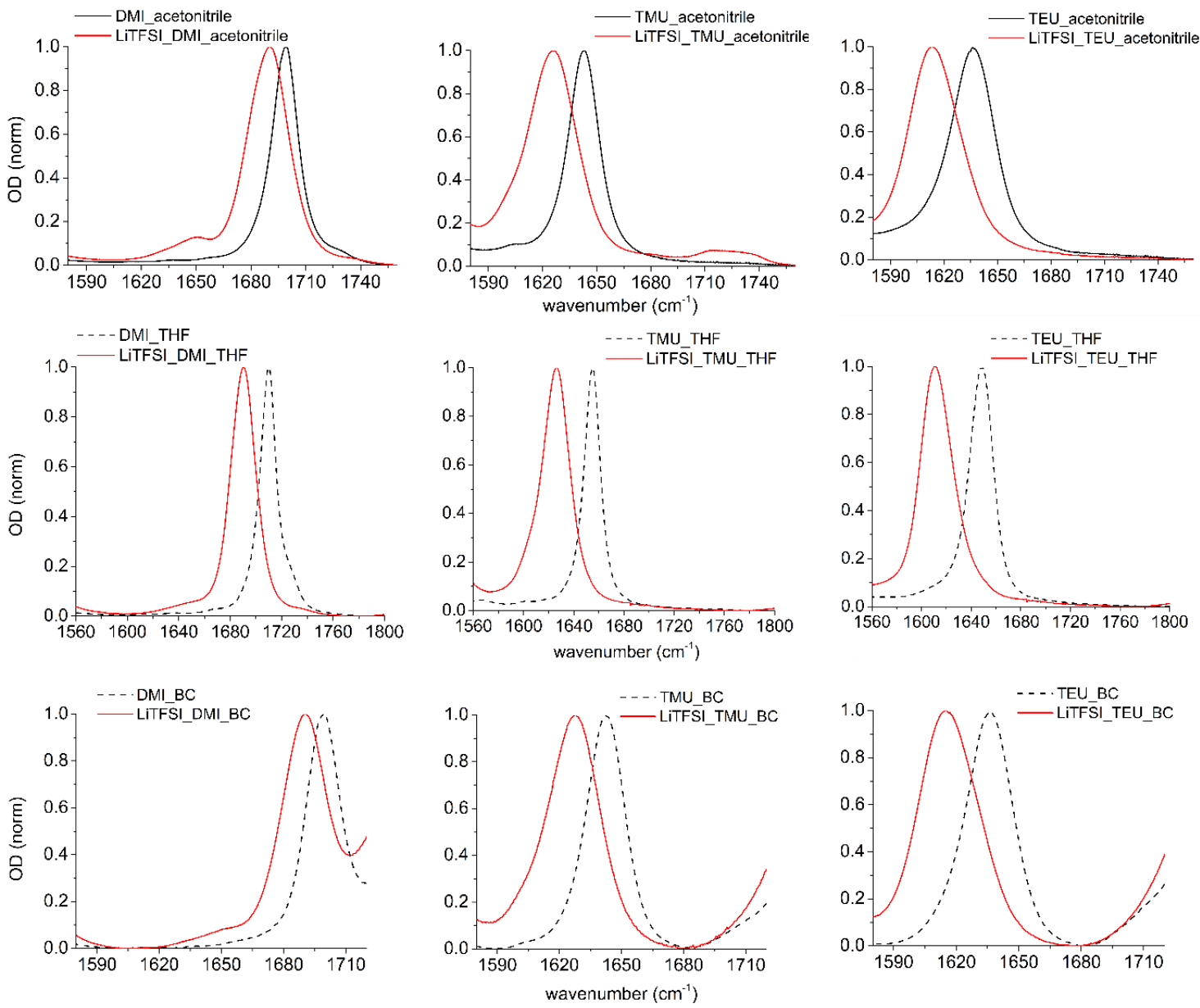

FIGURE S6. FTIR spectra of dilute experiments for LiTFSI in ureas and co-solvents. Molar ratio of LiTFSI:urea:co-solvent is 2:1:17. The upper panel shows the spectra in AN. The middle panel shows the spectra in THF. The lowest panel shows the spectra in BC. 
RAMAN SPECTRA OF 0.1 LiTFSI IN DMI, TMU AND TEU
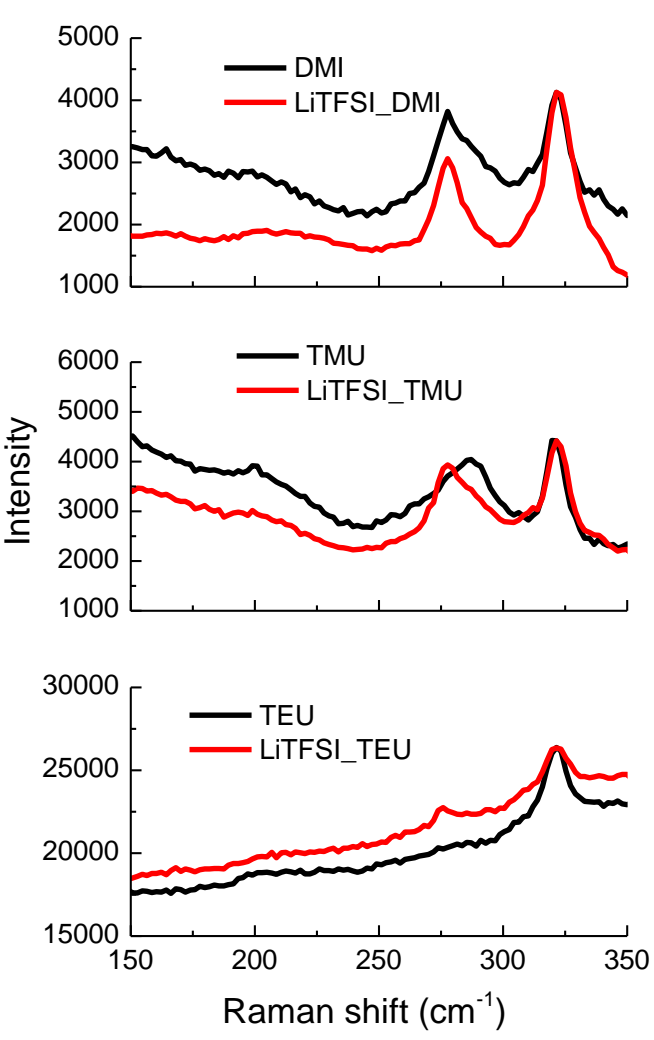

FIGURE S7. Raman spectra of 0.1 LiTFSI in ureas compared with the spectra of pure ureas.

POTENTIAL WELL OF UREA SOLVATION SHELL WITH RESPECT TO THE CHANGE IN ANGLE $\mathrm{Li}^{+}-\mathrm{O}=\mathrm{C}$

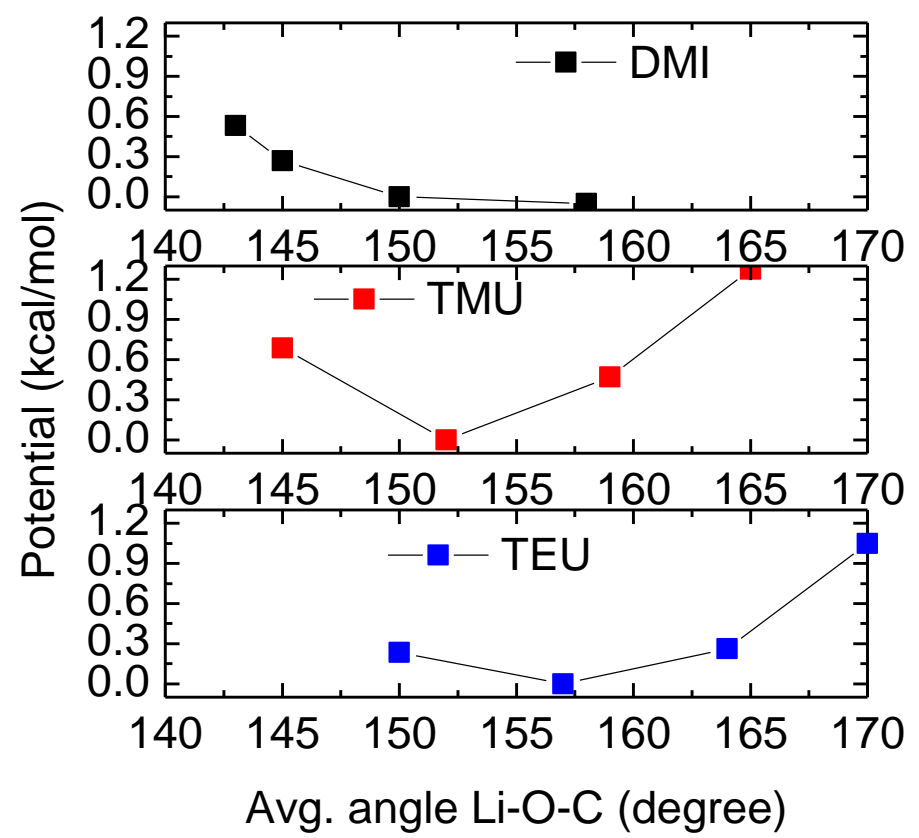

FIGURE S8. Potential of urea solvation shell vs. change in angle $\mathrm{Li}-\mathrm{C}=\mathrm{O}$. 
TABLE S1. Harmonic force constant $k$ of data in Fig. S5 with $V=\frac{1}{2} k\left(\theta-\theta_{0}\right)^{2}$.

\begin{tabular}{c|c}
\hline Type & $\begin{array}{c}\text { Force constant } \\
\mathrm{K}\left(\mathrm{kcal} /\left(\mathrm{mol}_{\text {.degree }}\right)\right)\end{array}$ \\
\hline DMI & 0.010 \\
TMU & 0.018 \\
TEU & 0.012 \\
\hline
\end{tabular}

\section{MODEL OF THE FTIR DATA FOR LiTFSI IN UREAS}

TABLE S2. Fitting parameters for concentration dependent FTIR data of LiTFSI in DMI, TMU and TEU. All frequencies and widths are reported in $\mathrm{cm}^{-1}$.

\begin{tabular}{|c|c|c|c|c|c|c|c|c|c|}
\hline \multirow[b]{2}{*}{ Solvent } & \multirow[b]{2}{*}{$\mathrm{X}\left(\mathrm{Li}^{+}\right)$} & \multicolumn{4}{|c|}{ Free Peak } & \multicolumn{4}{|c|}{$\mathrm{Li}^{+}$- coordinated peak } \\
\hline & & Freq. & FWHM & $\begin{array}{l}\text { Gaussian } \\
\text { Width }\end{array}$ & $\begin{array}{l}\text { Lorentz. } \\
\text { Width }\end{array}$ & Freq. & FWHM & $\begin{array}{l}\text { Gaussian } \\
\text { Width }\end{array}$ & $\begin{array}{l}\text { Lorentz. } \\
\text { Width }\end{array}$ \\
\hline \multirow{5}{*}{ DMI } & 0.000 & 1699.64 & 29.29 & 16.91 & 15.25 & - & - & - & - \\
\hline & 0.025 & 1700.00 & 31.44 & 15.55 & 20.28 & 1684.00 & 21.24 & 18.04 & 0.00 \\
\hline & 0.050 & 1700.17 & 31.34 & 13.68 & 22.63 & 1683.52 & 19.60 & 12.79 & 7.70 \\
\hline & 0.075 & 1700.73 & 29.67 & 10.72 & 23.97 & 1684.00 & 20.73 & 11.17 & 12.05 \\
\hline & 0.100 & 1702.32 & 27.33 & 5.13 & 25.90 & 1685.16 & 21.66 & 11.15 & 13.35 \\
\hline \multirow{5}{*}{ TMU } & 0.000 & 1648.78 & 29.57 & 25.11 & 0.00 & - & - & - & - \\
\hline & 0.025 & 1648.81 & 29.64 & 22.27 & 6.11 & 1621.93 & 21.09 & 0.00 & 21.09 \\
\hline & 0.050 & 1649.12 & 28.99 & 22.07 & 5.39 & 1623.34 & 21.30 & 0.00 & 21.30 \\
\hline & 0.075 & 1649.66 & 27.85 & 21.43 & 4.72 & 1624.08 & 21.68 & 0.00 & 21.68 \\
\hline & 0.100 & 1650.66 & 26.31 & 20.77 & 3.37 & 1625.38 & 21.55 & 3.98 & 20.46 \\
\hline \multirow{5}{*}{ TEU } & 0.000 & 1646.34 & 30.73 & 26.10 & 0.00 & - & - & - & - \\
\hline & 0.025 & 1646.44 & 31.44 & 24.17 & 5.37 & 1613.31 & 30.43 & 14.56 & 20.30 \\
\hline & 0.050 & 1646.21 & 30.96 & 23.97 & 4.95 & 1613.15 & 30.04 & 15.80 & 18.02 \\
\hline & 0.075 & 1646.30 & 30.36 & 23.48 & 4.91 & 1613.25 & 30.44 & 17.64 & 15.75 \\
\hline & 0.100 & 1646.35 & 29.07 & 22.81 & 4.02 & 1613.78 & 30.36 & 18.54 & 14.15 \\
\hline
\end{tabular}

\section{FREQUENCY CALCULATIONS OF CARBONYL STRETCH MODES OF DMI, TMU AND TEU}

TABLE S3. Results of DFT frequency calculations for free and coordinated carbonyl stretching mode frequencies in ureas and urea-based electrolytes. All frequencies in $\mathrm{cm}^{-1}$ and intensities in $\mathrm{km} / \mathrm{mol}$.

\begin{tabular}{|c|c|c|c|c|c|c|}
\hline \multirow{2}{*}{ Species } & \multicolumn{2}{|c|}{ Free } & \multicolumn{2}{|c|}{ Symmetric } & \multicolumn{2}{|c|}{ Asymmetric } \\
\hline & Freq. & Intensity & Freq. & Intensity & Freq. & Intensity \\
\hline \multirow{3}{*}{$\mathrm{Li}^{+}(\mathrm{DMI})_{4}$} & & & & & 1762.74 & 984.88 \\
\hline & 1816.84 & 508.67 & 1804.66 & 25.00 & 1765.10 & 1052.42 \\
\hline & & & & & 1769.27 & 969.42 \\
\hline \multirow{3}{*}{$\mathrm{Li}^{+}(\mathrm{TMU})_{4}$} & & & & & 1691.21 & 793.14 \\
\hline & 1753.81 & 415.31 & 1732.26 & 21.69 & 1694.74 & 1331.85 \\
\hline & & & & & 1696.85 & 599.42 \\
\hline \multirow{3}{*}{$\mathrm{Li}^{+}(\mathrm{TEU})_{4}$} & & & & & 1675.61 & 453.82 \\
\hline & 1740.59 & 346.49 & 1718.38 & 55.46 & 1677.23 & 888.21 \\
\hline & & & & & 1679.28 & 920.82 \\
\hline
\end{tabular}

